\title{
Seasonal vegetation response to climate change in the Northern
}

\section{Hemisphere (1982-2013)}

Dongdong Kong, Qiang Zhang, Vijay P Singh, Peijun Shi

\section{Corresponding author:}

Qiang Zhang, Ph.D. Professor,

Academy of Disaster Reduction and Emergency Management,

Beijing Normal University,

Beijing 100875, China

Tel: +86-10-58807068

E-mail: zhangq68@bnu.edu.cn (preferred contact address) 


\title{
Seasonal vegetation response to climate change in the Northern
}

\section{Hemisphere (1982-2013)}

Dongdong Kong ${ }^{1}$, Qiang Zhang ${ }^{2,3,4}$, Vijay P Singh ${ }^{5}$, Peijun $\mathrm{Shi}^{2,3,4}$

1. Department of Water Resources and Environment, Sun Yat-sen University, Guangzhou 510275, China;

2. Key Laboratory of Environmental Change and Natural Disaster, Ministry of Education, Beijing Normal University, Beijing 100875, China;

3. State Key Laboratory of Earth Surface Processes and Resource Ecology, Beijing Normal University, Beijing 100875, China;

4. Academy of Disaster Reduction and Emergency Management, Beijing Normal University, Beijing 100875, China;

5. Department of Biological and Agricultural Engineering and Zachry Department of Civil Engineering, Texas A\&M University, College Station, Texas, USA;

\begin{abstract}
This study investigated vegetation response to climate change exhibited by temperature, soil moisture, and solar radiation at Northern Hemisphere (NH) scale during the growing season and seasonal periods by analyzing satellite observations of vegetation activity and climatic data for a period of 1982-2013. Generally, About $75.8 \%$ of $\mathrm{NH}$ was dominated by increasing NDVI3g during growing season in 1982-2013, and 50.7\% significantly increase. Autumn NDVI3g is the main cause, with $77.7 \%$ increase $(45.0 \%$ significantly increase). The increasing tendency of greenness was stalled and even shifted to vegetation browning after 1994-1997
\end{abstract}


specifically in Central Europe, Northern North America, and Central Siberia. NDVI3g increase during the growing season shifts from 0.017 year $^{-1}$ to 0.006 year $^{-1}$, which mainly due to decreased spring NDVI3g and slowdown of summer NDVI3g increase. Specifically, three time intervals were identified with relatively peak NDVI3g, i.e., 1990, 1997 and 2010, and three time intervals with trough NDVI3g, i.e., 1983, 1992-1994, 2002-2005. The factors potentially influencing vegetation growth in different parts of NH are complex and varied. Temperature is recognized as the critical factor behind vegetation greenness in high latitudes especially for spring and autumn temperature, in North America and Siberia. Soil moisture is the key factor influencing vegetation growth in Central Canada, Eastern USA and Western Africa. And solar radiation is corresponding to vegetation trend in North part of North America, Eastern China. This study helps identify key factors for vegetation changes and understand vegetation response to climate change at $\mathrm{NH}$ scale.

Key words: Northern Hemisphere; climate change; Normalized Difference Vegetation Index (NDVI); Vegetation response;

\section{Introduction}

Terrestrial ecosystems and climate components interact via exchanges of energy, moisture, trace gases, aerosols and momentum between the land surface and atmosphere (Shukla and Mintz, 1982; Bonan et al., 1992; Pielke et al., 1998). 
Intensive discussions have occurred on the impact of climate change on ecosystems. As a result of spring and summer cooling, summer vegetation browning trends have occurred in North America since the early 1990s (Wang et al., 2011). In addition, asymmetric diurnal warming leads to divergent responses of $\mathrm{NH}$ vegetation growth and carbon sequestration to rising temperatures (Peng et al., 2013). However, there are discrepancies pertaining to relations between climate change and vegetation response. Some researchers have identified warming spring and autumn in northern latitudes over the past two decades (Mitchell and Jones, 2005) and synchronous greening trends with lengthening growth season and greater photosynthetic activities (Myneni et al., 1997; Zhou et al., 2001), and subsequent enhancement of carbon sequestration which results in the loss of carbon dioxide due to spring and autumn warming (e.g. Piao et al., 2008). Global investigation of vegetation response to climatic change from 1982-1999 also corroborated a 6\% increase in the net primary production (NPP) due to enhanced plant growth in northern mid-latitudes and high latitudes, resulting from increasing temperature and solar radiation relaxed climate constraints. (Nemani et al., 2003). However, a recent study showed that suitable growing day would decrease globally by up to $11 \%$ when other climatic variables, such as temperature, water availability, and solar radiation that limit plant growth, were considered (Mora et al., 2015). Furthermore, Zhao et al. (2009) found a decrease in the net primary productivity during the 2000s, because large-scale droughts have reduced regional NPP, and a drying trend in the Southern Hemisphere has decreased NPP in recent decades. This shows that vegetation response to climate 
change at the global scale is a critical scientific issue that is far from being answered and needs further investigation.

Respiration and NPP are a major driver of terrestrial carbon-sink dynamics (Nemani et al., 2003). The carbon balance of terrestrial ecosystems is highly sensitive to climate change (Goulden et al., 1998; Bergeron et al., 2007; Piao et al., 2008). Nowadays, a majority of researches have focused on such issues as vegetation response to a specific climate variable, e.g., temperature (e.g. Myneni et al., 1997; Piao et al., 2007; Peng et al., 2013), drought stress (e.g. Vicente-Serrano et al., 2013; Ukkola et al., 2015), seasonal drying/warming (e.g. Parida and Buermann, 2014; Buermann et al., 2014), and atmospheric $\mathrm{CO}_{2}$ (Leakey et al., 2009). However factors influencing vegetation changes are complicated and still have a fierce controversy due to limited knowledge about vegetation response at the global scale (Nemani et al., 2003; Piao et al., 2008; Zhao et al. 2009). Additionally, many studies of vegetation long-term activity change were regional (Zhou et al., 2001; White et al., 2009; Zhu et al., 2012; Garonna et al., 2014). Temperature, radiation and water interact to impose complex and varying limitations on vegetation activity in different parts of the world (Nemani et al., 2003). Temperature influence plant photosynthesis and respiration (Peng et al., 2013), also is the primary factor determining growing season onset (Piao et al., 2015) and cessation (Piao et al., 2008). Solar radiation is the energy of photosynthesis, which initiates photosynthesis when absorbed and converted to electronic excitation energy (Gust et al., 2001). Comparing with precipitation, soil moisture can reflect plant water available directly (Liu et al., 2013). 
Continuous low soil moisture can induce plant high water stress and cessation of transpiration and photosynthesis (Breshears et al., 2005). Temperature, soil moisture and solar radiation can be considered as the major factors influencing vegetation. Moral et al. (2015) also used temperature, soil moisture and solar radiation to investigate plant growth suitable days. Furthermore, Seddon et al. (2016) treated air temperature, water availability, cloud-cover as the main driving factors similarly. Vegetation-climate interactions are nonlinear and complex, and hence the relationship between vegetation and climate variables still have a fierce controversy and is hard to simulate and quantify the relative contribution of individual climate factors. Visual comparison can simplify the simulating progress, which could probably find some meaningful results (Piao et al., 2011; Wang et al., 2011). In our study, we present an investigation of vegetation response to climate change in terms of temperature, soil moisture, and solar radiation during growing season and seasonal periods by analyzing satellite observations of vegetation activity and climatic data for a period of 1982-2013 at NH scale by visual comparison. The study aims to provide a global overview of principal influencing factors for vegetation changes in specific regions of $\mathrm{NH}$.

\section{Data and methodology}

\subsection{Data}

Seasonal and interannual global vegetation variability, reflected by normalized difference vegetation index (NDVI), assumes that NDVI contains clues about the 
vegetation response to climate change (Zhou et al., 2001; Buitenwerf et al., 2015). NDVI has been widely used in the quantification of biomass, leaf phenology and net primary production (Buitenwerf et al., 2015), growing trends (Piao et al., 2005; Wang et al., 2011; Garonna et al., 2014) and growing processes (Buitenwerf et al., 2015) of vegetation. NDVI used in this study is GIMMS-NDVI version 3g (Global Inventor Modeling and Mapping Studies) with a resolution of $0.083^{\circ}$ covering the period of July 1981 to December 2013 at half month interval (Pinzon and Tucker, 2014; Buermann et al., 2014). NDVI has been corrected for orbital drift effects, calibration, viewing geometry, stratospheric volcanic aerosols and other errors unrelated to vegetation change (Pinzon and Tucker, 2014; Garonna et al., 2014). Besides, to eliminate white noise points from various sources, the maximum value composite (MVC) was used to accumulate NDVI3g dataset (Holben et al., 1986). Regions with NDVI $<0.1$ during the growing season (April to October) were assumed to be barren and such regions were excluded from analysis (Piao et al., 2005; Garonna et al., 2014). Climatic variables potentially impacting vegetation changes considered in this study were temperature, soil moisture and solar radiation. The meteorological dataset such as temperature, solar radiation and soil moisture, was from NCEP/NCAR reanalysis data extracted from National Center for Environment Prediction (NCEP) (http://www.esrl.noaa.gov/psd/data/reanalysis/reanalysis.shtml) (Kalnay et al., 1996; Nemani et al., 2003). NCEP/NCAR reanalysis data is one of the longest running reanalysis that uses rawindsonde data, and was used in many publications. Thus it 
can be used as a baseline reference for many computations (Kalnay et al., 1996). Mora et al. (2015) also used NCEP/NCAR reanalysis data to analyze suitable days for plant growth.

\subsection{Methodology}

Turn point of NDVI3g and climate variables was detected using piecewise regression (Eq. 1), which has been widely used in the study of ecosystems (Wang et al., 2011; Jong et al., 2012; Garonna et al., 2015). Besides, trends of NDVI3g and climate variables before and after turn point, were evaluated using the least linear regression method.

$$
y= \begin{cases}\beta_{0}+\beta_{1} t+\varepsilon & t \leq \alpha \\ \beta_{0}+\beta_{1} t+\beta_{2}(t-\alpha)+\varepsilon & t>\alpha\end{cases}
$$

Where $t$ is year; $y$ is seasonal NDVI3g or climate variables; $\alpha$ is the turn point; $\beta_{0}, \beta_{1}, \beta_{2}$ are regression coefficients, and $\varepsilon$ is the residual of the fit. In order to avoid linear regression in one period with too few data points, we restrict $\alpha$ within the period 1986 to 2009 (Wang et al., 2011).

\section{Results and discussion}

\subsection{Seasonal trends in NDVI3g and climate variables}

The period of 1982-1997 exhibited increasing NDVI3g. Apparent stalling of vegetation greening can be observed after 1997. The increasing magnitude of NDVI3g during the growing season decreased from 0.0017 year ${ }^{-1}\left(\mathrm{R}^{2}=0.671, \mathrm{p}=\right.$ $0.000)$ to $0.0006\left(\mathrm{R}^{2}=0.183, \mathrm{p}=0.098\right)$. NDVI3g was decreasing but not statistically significant. Stalling of vegetation greening was caused mainly by the decrease of 
NDVI3g during spring and a slight increase of NDVI3g during summer. This observation is partly in agreement with Piao et al. (2011) that the trend in vegetation greening during summer was stalled or reversed during 1997-2006, which could be due to different lengths of the study period. Hence, this study used longer NDVI3g series which can update our knowledge of vegetation changes over NH Soil moisture persistently decreased (Fig. 1c) and solar radiation shifted from increase to decrease after 1997. Specifically, the changing magnitude of summer solar radiation shifted from 0.095 year $^{-1}\left(R^{2}=0.162, p=0.121\right)$ to $-0.1642\left(R^{2}=0.300, p=0.028\right)$.

Vegetation changes are sensitive to temperature changes, particularly in boreal and temperate regions in NH. Wang et al. (2011) attributed vegetation browning in North America to spring cooling. However, spring cooling cannot be identified from the viewpoint of $\mathrm{NH}$ (Figs. 1b, 1f, $1 \mathrm{j}$ and $1 \mathrm{~g}$ ) with the increasing trend of growing season temperature from 0.0089 year $^{-1}\left(R^{2}=0.025, p=0.559\right)$ to $0.0436\left(R^{2}=0.508\right.$, $\mathrm{p}=0.001)$. This points to different regional variations of seasonal temperature and global investigation may mask regional differences. Therefore, vegetation response to climate change at the seasonal scale and for specific regions from a global viewpoint was investigated. Specifically, three time intervals were identified with relatively peak NDVI3g, i.e., 1990, 1997 and 2010, and three time intervals with trough NDVI3g, i.e., 1983, 1992-1994, 2002-2005. The three intervals with vegetation greening matched the intervals with peaks of temperature and soil moisture (Fig. 1). The trough values of NDVI3g were identified around 1992, which can be caused by $\mathrm{NH}$ cooling due to Pinatubo eruption (Lucht et al., 2002). The trough temperature values and relative 
trough soil moisture values during 1992 can also be observed from Fig. 1. These two factors combine to trigger significant vegetation browning during the study period. However, solar radiation changes were not corresponding to vegetation changes during Pinatubo eruption (Nemani et al., 2003) which showed limited impacts on vegetation changes.

3.2. Vegetation response to climate change during the growing season

Trends in NDVI3g over NH (Fig. 2a) indicate that vegetation greening is in the dominant position (about $75.8 \%$ for increase, and $50.6 \%$ for significant increase). NDVI3g greening is particularly obvious in high latitude of North America and Siberia, central part of Canada, east coast of USA, most regions of Europe, north and south China, and central Pacific region. These results are consistent with those of Myneni et al. (1997), Zhou et al. (2001) and Piao et al. (2011). Changes in $\mathrm{CO}_{2}$, nitrogen deposition and human activities, such as land use changes and forestation/deforestation, play a critical role in vegetation growth. However, increasing NDVI3g is closely related to changes of climatic variables (Figs. 2b-2d), e.g., it is generally assumed that vegetation growth is highly sensitive to temperature changes at the beginning and end of growing season (Tanja et al., 2003; Piao et al., 2011), particularly in temperate and boreal regions. The increasing magnitude of temperature in high latitudes of North America, western Europe and most regions of Siberia can reach $0.04^{\circ} \mathrm{Cyear}^{-1}$ and even $0.1^{\circ} \mathrm{Cyear}^{-1}$ in some regions. Vegetation changes in high latitudes are highly sensitive to temperature variations (Wang et al., 
2011), particularly in spring and autumn (Piao et al., 2008, 2011). Vegetation greening in boreal regions can be attributed to increasing temperature. Impacts of droughts on vegetation growth have been corroborated (Allen and Breshears, 1998; Breshears et al., 2005; Vicente-Serrano et al., 2013) and soil moisture depletion can enhance the severity of drought (Fischer et al., 2007) and hence soil moisture changes can potentially influence vegetation phenology, especially in semi-arid regions (Liu et al., 2013). Spatial patterns of increasing trends in NDVI3g match those of soil moisture in central Canada, eastern USA and western Africa and the availability of soil moisture in these regions is the critical limiting factor for vegetation growth. Furthermore increasing solar radiation in eastern China (about $1 \mathrm{~W} / \mathrm{m}^{2}$ year ${ }^{-1}$ ) and increasing temperature in northern China are in line with greening-up of vegetation and hence temperature and solar radiation can be regarded as factors constraining vegetation growth. Vegetation greening in these regions can help enhance carbon sequestration and carbon uptake can be expected in the future if the constraining factors extend to increase.

Vegetation greening shifted to vegetation browning during 1994-1997 with different specific turn points over NH (Figs. 3a, 3d, 3g, 3j). Vegetation greening was dominant over $81.6 \%$ of $\mathrm{NH}$ and significant increasing NDVI3g was detected over $40 \%$ of $\mathrm{NH}$ before turn points. Vegetation browning was observed after turn points over $44.1 \%$ of $\mathrm{NH}$ and significant decreasing NDVI3g was found over $20.5 \%$ of $\mathrm{NH}$, specifically in Alaska, high latitudes of North America, regions around the Black Sea and Caspian Sea, central Siberia, southwestern Asia, central Africa, and coastal 
regions of eastern Asia. However, persistent increasing NDVI3g after turn points, i.e. 1994-1997, was observed in other regions over NH, such as central Canada, east coast of North America, Western Europe, and eastern China. Even more evident increase of NDVI3g was found in some regions, such as high latitude of Canada, and northeastern and northern Siberia which are dominated by significant warming climate (Figs. 3e, 3f). This study observed apparent warming trends of climate after around 1997 in high latitudes, such as North America, Europe, Northern Siberia, Kazakhstan, South Mexica and these regions were dominated by shifts from deceasing to increasing temperature with an increasing magnitude of $0.1^{\circ} \mathrm{C}$ year ${ }^{-1}$ (Figs. $3 \mathrm{~d}, 3 \mathrm{~g}$ and $3 \mathrm{j}$ ). The lengthening growing season benefited significant vegetation greening in high and temperate latitudes (Zhou et al., 2001; White et al., 2009; Zhu et al., 2012). Therefore, it is not the case that vegetation greening or browning exhibits an increasing or a decreasing tendency globally, implying complex and varying limitations on vegetation activity in different parts of the world (Churkina and Running, 1998; Nemani et al., 2003; Buitenwerf et al., 2015). Soil moisture had moderate changes and had a persistent increase after turn points in eastern North America, southern Mexica, regions near the $10^{\circ} \mathrm{N}$ in Africa, southwestern China, and western coast of Europe. It is assumed that temperature is the key potential influencing factor for vegetation growth from a global viewpoint. However, vegetation growth-limiting factors are varying in different parts of NH. Soil moisture can act as the critical influencing factor in arid and semiarid regions (Liu et al., 2013). It is interesting to find that solar radiation shifted to decrease after turn points in tropical regions except eastern China 
and South America. However, vegetation variations should be the combined result of various factors, such as temperature, soil moisture, solar radiation and even human activities like forestation/deforestation.

3.3. Vegetation response to climate change during spring, summer and autumn

Comparison of Figs. 4, 6 and 8 indicates a large-scale increase of NDVI3g during the growing season, about $75.8 \%$ of $\mathrm{NH}$ was dominated by increasing NDVI3g and the increase of NDVI3g over $50.7 \%$ of $\mathrm{NH}$ was significant. This NDVI3g increase should be attributed to the NDVI3g increase during autumn (Garonna et al., 2014). In autumn, about $77.7 \%$ of $\mathrm{NH}$ was dominated by increasing NDVI3g and $45 \%$ of $\mathrm{NH}$ was characterized by significant increasing NDVI3g with an increasing magnitude of 0.002 year $^{-1}$ (Fig. 8). This can be well explained by significant autumnal warming at the subcontinental (Piao et al., 2008) or even regional scale (IPCC, 2007). This kind of booming autumn vegetation can be considered as the major factor triggering significant sequestration of carbon dioxide (Piao et al., 2008, IPCC, 2007). Even so, the increasing tendency stalled after a period of 1994-1997 and even a decrease in NDVI3g occurred after the turn points, specifically in central Europe, northern North America, and central Siberia. Besides, a general increase of autumnal temperature was observed in high latitudes after turn points (Figs. 9e, 9f). The temperature increase can potentially lengthen the growing season and greening trends can be expected (Buermann et al., 2014; Garonna et al., 2014). However, soil moisture can sometimes have larger impacts on vegetation 
growth (Figs. 9h, 9i). Soil moisture deficit can be regarded as the principal cause behind the decrease of NDVI3g in central Europe and central Siberia and the decrease of soil moisture and solar radiation are believed to be the major factor behind vegetation browning in North America.

The shift of NDVI3g from increase to decrease during 1994-1997 was found during spring and summer, $45.0 \%$ and $72.3 \%$ of $\mathrm{NH}$ was dominated by increased NDVI3g before turn points and $32.1 \%$ and $33.5 \%$ of $\mathrm{NH}$ was dominated by decreased NDVI3g after turn points during spring and summer, respectively. Spring vegetation browning was identified in high latitudes of North America, North Africa, central and eastern Siberia, and southwestern Asia (Figs. 5b, 5c). A significant spring temperature decrease was observed in central and eastern North America and central Europe (Fig. 3b) and parts of $\mathrm{NH}$ were characterized by slight increasing spring temperatures, such as North America (Figs. 5e, 5f). Vegetation browning in recent years (Wang et al., 2011) is the combined result of temperature changes and decreased solar radiation. Significant warming in central Europe is good for vegetation growth, however, decreased soil moisture further offset vegetation growth due to significant climate warming and these two factors combine to cause slow vegetation grown in central Europe. In southeastern China, vegetation greenness can be attributed to warming climate and increased solar radiation, though soil moisture is decreasing (Figs. 5h, 5i). Humid climate in southeastern China alleviates negative impacts of soil moisture decrease on vegetation growth.

Vegetation greenness during summer (Fig. 6) can be observed mainly in high 
latitudes of $\mathrm{NH}$, northern North America, central Canada, Western Europe and eastern Siberia (Fig. 6a). Solar radiation is increasing in Europe and Siberia and the direction of trends in soil moisture and that in vegetation growth are adverse, implying that solar radiation and temperature changes are the factors critically influencing vegetation growth in these aforementioned regions. However, the direction of trends in soil moisture is in line with that in vegetation growth, indicating soil moisture can be taken as the key cause behind vegetation variations in central Canada. Vegetation browning is seen mainly in southern North America, northern Africa, regions around Caspian Sea, central Siberia, and southwestern Asia. Soil moisture deficit has increased during summer in recent years, triggering a decrease of summer NDVI3g (Figs. 7e, 7f). Warming climate is believed to benefit vegetation growth. However, warming climate and increased solar radiation can greatly enhance vegetation respiration and evapotranspiration, and hence increased soil moisture deficit (Figs. 7e, 7f). Drought or water-stress caused by higher temperatures can be regarded as one of the major causes behind vegetation browning (Pielke et al., 1998; Seneviratne et al., 2010). Thus, water-stress should be the major cause behind summer vegetation browning in the regions around Caspian Sea. In addition, field fires can be one of reasons for decreased NDVI3g (Pielke et al., 1998). Vegetation browning in southwestern Asia is the result of decreased solar radiation and water stress, though temperature is increasing in these regions. Decreased summer NDVI3g in Siberia should be due to the lag effect of decreased NDVI3g during spring (Fig. 5c). However, due to warming spring, regions with decreased 
NDVI3g have shrunk greatly in recent years (Figs. 7e, 7f)

\section{Conclusions}

This study investigates a global scale vegetation response to climate change in terms of temperature, soil moisture, and solar radiation during the growing season and seasonal periods by analyzing satellite observations of vegetation activity and climatic data covering a period of 1982-2013.

Results identified three time intervals with relatively peak NDVI3g, i.e., 1990, 1997 and 2010, and three time intervals with trough NDVI3g, i.e., 1983, 1992-1994, 2002-2005. Stalling of vegetation greenness was identified after 1997 over NH. NDVI3g during the growing season shifts from an increase of 0.017 year $^{-1}$ to a slight increase of 0.006 year $^{-1}$. The slowdown of vegetation greenness after 1997 is attributed to decreased NDVI3g during spring and a slow increase of NDVI3g during summer. The decrease of solar radiation and soil moisture is believed to be the major cause. Soil moisture is persistently decreasing and solar radiation shifts from increase to decrease after 1997 and it is particularly true for changes in summer radiation which shifts from 0.0965 year $^{-1}$ to -0.1642 year $^{-1}$. In addition, it is interesting to find that from a global viewpoint, spring warming in $\mathrm{NH}$ is continuous and specifically a warming trend of the growing season shifts from 0.0089 year $^{-1}$ to 0.0436 year $^{-1}$.

Vegetation trend shifting from greening to browning was detected with the turn point of 1997 in $\mathrm{NH}$, which mainly caused by spring and summer vegetation trend decreasing. Specifically, $75.8 \%$ of $\mathrm{NH}$ is dominated by vegetation greening during the 
growing season, which may be due to significant autumnal vegetation greenness. However, $32.1 \%$ and $33.5 \%$ of $\mathrm{NH}$ are characterized by vegetation browning during spring and summer, respectively. Spring vegetation browning can be identified in high latitudes of North America, North Africa, central and eastern Siberia, and southwestern Asia. Summer vegetation greenness can be observed mainly in high latitudes of $\mathrm{NH}$, northern North America, central Canada, Western Europe, and eastern Siberia. Shifts of autumnal vegetation greening to browning can be found in central Europe, northern North America, and central Siberia.

However, the factors potentially influencing vegetation growth in different parts of $\mathrm{NH}$ are complex and varied. Warming tendency and lengthening growing season are believed to be the major factors behind vegetation greening in high latitudes of $\mathrm{NH}$; and water stress and solar radiation can be regarded as the major causes behind vegetation greening or browning in arid and semiarid regions. However, temperature, soil moisture and solar radiation can combine to influence vegetation variation and vice versa (e.g. Seneviratne et al., 2010). Besides, warming climate is believed to benefit vegetation growth. However, warming climate and increased solar radiation can greatly enhance vegetation respiration and evapotranspiration, and hence increase soil moisture deficit (Seneviratne et al., 2010; Vicente-Serrano et al., 2013). This study helps understand vegetation greening or browning over $\mathrm{NH}$ in both time and space and also related influencing factors in different parts of $\mathrm{NH}$.

\section{Acknowledgments}


This work is financially supported by the National Science Foundation for Distinguished Young Scholars of China (Grant No.: 51425903), the Natural Foundation of Anhui Province (Grant No.: 1508085MD65), and is fully supported by a grant from the Research Grants Council of the Hong Kong Special Administrative Region, China (Project No. CUHK441313). Detailed information such as data can be obtained by writing to the corresponding author at zhangq68@mail.sysu.edu.cn. All authors stated no any potential sources of conflict of interest. Our cordial gratitude should be extended to the editor, Prof. Dr. Sierd Cloetingh, and two anonymous reviewers for their professional and pertinent comments and suggestions which are greatly helpful for further improvement of the quality of this manuscript.

\section{References}

Allen, C.D. and Breshears, D.D., 1998. Drought-induced shift of a forest-woodland ecotone: Rapid landscape response to climate variation. Proceedings of the National Academy of Sciences 95(25), 14839-14842.

Bergeron, O., Margolis, H.A., Black, T.A., Coursolle, C., Dunn, A.L., Barr, A.G., Wofsy, S.C., 2007. Comparison of carbon dioxide fluxes over three boreal black spruce forests in Canada. Glob. Change Biol. 13, 89-107.

Bonan, G.B., Pollard, D., Thompson, S.L., 1992. Effects of boreal forest vegetation on global climate. Nature 359, 716-718.

Breshears, D.D., Cobb, N.S., Rich, P.M., Price, K.P., Allen, C.D., Balice, R.G., Romme, W.H., Kastens, J.H., Floyd, M.L., Belnap, J., Anderson, J.J., Myers, 
O.B., Meyer, C.W., 2005, Regional vegetation die-off in response to global-change-type drought. Proceedings of the National Academy of Sciences 102(42), 15144-15148.

Buermann, W., B. Parida, M. Jung, G.M., MacDonald, C.J. Tucker, and M. Reichstein, 2014. Recent shift in Eurasian boreal forest greening response may be associated with warmer and drier summers. Geophys. Res. Lett. 41, 1995-2002.

Buitenwerf, R., Rose, L., and Higgins, S.I., 2015. Three decades of multi-dimensional change in global leaf phenology. Nature Climate Change 5, 364-368.

Churkina, G., S.W. Running, 1998. Contrasting climatic controls on estimated productivity of global terrestrial biomes. Ecosystems 1(2), 206-215.

Fischer, E.M., Seneviratne, S.I., Vidale, P.L., Luthi, D., and Schar, C., 2007. Soil moisture-atmosphere interactions during the 2003 European summer heat wave. Journal of Climate 20, 5082-5099.

Garonna, I., de Jong, R., de Wit, A.J.W., Mücher, C.A., Schmid, B., Schaepman, M.E., 2014. Strong contribution of autumn phenology to changes in satellite-derived growing season length estimates across Europe (1982-2011). Global Change Biology 20(11), 3457-3470.

Garonna, I., De Jong, R., Schaepman, M.E., 2015. Variability and evolution of global land surface phenology over the past three decades (1982-2012). Global Change Biology DOI: 10.1111/gcb.13168. 
Goulden, M.L., S.C. Wofsy, J.W. Harden, S.E. Trumbore, P.M. Crill, S.T. Gower, T. Fries, B.C. Daube, S.-M. Fan, D.J. Sutton, A. Bazzaz, J.W. Munger., 1998. Sensitivity of boreal forest carbon balance to soil thaw. Science 279(5348), 214-217.

Holben, B.N., 1986. Characteristics of maximum-value composite images from temporal AVHRR data. International Journal of Remote Sensing 7(11), $1417-1434$.

IPCC. Climate Change 2007: The Physical Sciences Basis: Contribution of Working Group I to the Fourth Assessment Report of the Intergovernmental Panel on Climate Change, Cambridge University Press, Cambridge, 2007.

Jong, R., Verbesselt, J., Schaepman, M.E., Bruin, S., 2012. Trend changes in global greening and browning: contribution of short-term trends to longer-term change. Global Change Biology 18(2), 642-655.

Kalnay, E., M. Kanamitsu, R. Kistler, W. Collins, D. Deaven, L. Gandin, M. Iredell, S. Saha, G. White, J. Woollen, Y. Zhu, A. Leetmaa, R. Reynolds, M. Chelliah, W. Ebisuzaki, W. Higgins, J. Janowiak, K.C. Mo, C. Ropelewski, J. Wang, R. Jenne, and D. Joseph, 1996. The NCEP/NCAR 40-Year Reanalysis Project. Bull. Amer. Meteor. Soc. 77, 437-471.

Leakey, A.D., Ainsworth, E.A., Bernacchi, C.J., Rogers, A., Long, S.P., Ort, D.R., 2009. Elevated $\mathrm{CO}_{2}$ effects on plant carbon, nitrogen, and water relations: six important lessons from FACE. J. Exp. Bot. 60(10), 2859-2876.

Liu, H., F. Tian, H.C. Hu, H.P. Hu, and M. Sivapalan, 2013. Soil moisture controls 
on patterns of grass green-up in Inner Mongolia: an index based approach. Hydrol. Earth Syst. Sci. 17, 805-815.

Lucht, W., Prentice, I.C., Myneni, R.B., Sitch, S., Friedlingstein, P., Cramer, W., Bousquet, P., Buermann, W., Smith, B., 2002. Climatic control of the high-latitude vegetation greening trend and Pinatubo effect. Science 296, $1687-1689$.

Myneni, R.B., Keeling, C.D., Tucker, C.J., Asrar, G. \& Nemani, R.R., 1997. Increased plant growth in the northern high latitudes from 1981 to 1991. Nature $386,698-702$.

Mitchell, T.D. and Jones, P.D., 2005. An improved method of constructing a database of monthly climate observations and associated high-resolution grids. International Journal of Climatology 25, 693-712.

Mora, C., Caldwell, I.R., Caldwell, J.M., Fisher, M.R., Genco, B.M., Running, S.W., 2015. Suitable days for plant growth disappear under projected climate change: potential human and biotic vulnerability. PLOS Biology DOI: 10.1371/journal.pbio.1002167.

Nemani, R.R., Keeling, C.D., Hashimoto, H., Jolly, W.M., Piper, S.C., Tucker, C.J., Myneni, R.B., Running, S.W., 2003. Climate-driven increases in global terrestrial net primary production from 1982-1999. Science 300, 1560-1563.

Parida, B.R. and Buermann,W., 2014. Increasing summer drying in North American ecosystems in response to longer nonfrozen periods. Geophysical Research Letters 41, 5476-5483. 
Peng, S., Piao, S., Ciais, P., Myneni, R.B., Chen, A., Chevallier, F., Dolman, A.J., Janssens, I.A., Peñuelas, J., Zhang, G., Vicca, S., Wan, S., Wang, S., and Zeng, H., 2013. Asymmetric effects of daytime and night-time warming on Northern Hemisphere vegetation. Nature 501, 88-92.

Piao, S.L., Fang, J., Zhou, L., Zhu, B., Tan, K., Tao, S., 2005. Changes in vegetation net primary productivity from 1982 to 1999 in China. Global Biogeochemical Cycles 19(2), DOI: 10.1029/2004GB002274.

Piao, S.L., Ciais, P., Friedlingstein, P., Peylin, P., Reichstein, M., Luyssaert, S., Margolis, H., Fang, J.Y., Barr, A., Chen, A.P., Grelle, A., Hollinger, D.Y., Laurila, T., Lindroth, A., Richardson, A.D., Vesala, T., 2008. Net carbon dioxide losses of northern ecosystems in response to autumn warming. Nature 451, 49-53.

Piao, S.L., Wang, X., Ciais, P., Zhu, B., Wang, T., and Liu, J., 2011. Changes in satellite-derived vegetation growth trend in temperate and boreal Eurasia from 1982-2006. Global Change Biology 17, 3228-3239.

Pielke, R.A., Avissar, R., Raupach, M., Dolman, A.J., Zeng, X., Denning, A.S., 1998. Interactions between the atmosphere and terrestrial ecosystems: influence on weather and climate. Global Change Biology 4, 461-475.

Pinzon, J.E., Tucker, C.J., 2014. A non-stationary 1981-2012 AVHRR NDVI3g time series. Remote Sensing 6(8), 6929-6960.

Seddon, A. W., Macias-Fauria, M., Long, P. R., Benz, D., \& Willis, K. J. (2016). Sensitivity of global terrestrial ecosystems to climate variability. Nature, 531(7593), 229-232. 
Seneviratne, S.I., Corti, T., Davin, E.L., Hirschi, M., Jaeger, E.B., Lehner, I., Orlowsky, B., Teuling, A.J., 2010. Investigating soil moisture-climate interactions in a changing climate: A review. Earth-Science Reviews 99(3-4), 125-161.

Shukla, J. and Mintz, Y., 1982. Influence of land-surface evapotranspiration on the Earth's climate. Science 215, 1498-1501.

Tanja, S., Berninger, F., Vesala, T., Markkanen, T., Hari, P., Mäkelä, A., IIvesniemi, H., Hänninen, H., Nikinmaa, E., Huttula, T., Laurila, T., Aurela, M., Grelle, A., Lindroth, A., Arneth, A., Shibistova, O., LIoyd, J., 2003. Air temperature triggers the recovery of evergreen boreal forest photosynthesis in spring. Global Change Biology 9(10), 1410-1426.

Ukkola, A.M., I.C. Prentice, T.F. Keenan, A.I.J.M. van Dijk, N.R. Viney, R.B. Myneni and J. Bi., 2015. Reduced streamflow in water-stressed climates consistent with $\mathrm{CO} 2$ effects on vegetation. Nature Climate Change DOI: 10.1038/NCLIMATE2831.

Vicente-Serrano, S.M., C. Gouveia, J.J. Camarero, S. Beguería, R. Trigo, J.I. López-Moreno, C. Azorín-Molina, E. Pasho, J. Lorenzo-Lacruz, J. Revuelto, E. Morán-Tejeda, and A. Sanchez-Lorenzo, 2013. Response of vegetation to drought time-scales across global land biomes. Proceedings of the National Academy of Sciences 110(1), 52-57.

Wang, X., Piao, S., Ciais, P., Li, J., Friedlingstein, P., Koven, C., and Chen, A., 2011. Spring temperature change and its implication in the change of vegetation 
growth in North America from 1982 to 2006. Proceedings of the National Academy of Sciences 108(4), 1240-1245.

White, M.A., De Beurs, K.M., Didan, K., Inouye, D.W., Richardson, A.D., Jensen, O.P., O’keefe, J., Zhang, G., Nemani, R.R., Van Leeuwen, W.J.D., Brown, J.F., Wit, A.D., Schaepman, M., Lin, X., Dettinger, M., Bailey, A.S., Kimball, J., Schwartz, M.D., Baldocchi, D.D., Lee, J.T., Lauenroth, W.K., 2009. Intercomparison, interpretation, and assessment of spring phenology in North America estimated from remote sensing for 1982-2006. Global Change Biology 15(10), 2335-2359.

Zhao, M. and Running, S.W., 2010. Drought-induced reduction in global terrestrial net primary production from 2000 through 2009. Science 329, 940-943.

Zhou, L.M., Tucker, C.J., Kaufmann, R.K., Slayback, D., Shabanov, N.V., and Myneni, R.B., 2001. Variations in northern vegetation activity inferred from satellite data of vegetation index during 1981 to 1999. Journal of Geophysical Research 106, 20069-20083.

Zhu, W.Q., H. Tian, X. Xu, Y. Pan, G. Chen and W. Lin, 2012. Extension of the growing season due to delayed autumn over mid and high latitudes in North America during 1982-2006. Global Ecology and Biogeography 21(2), 260-217. 


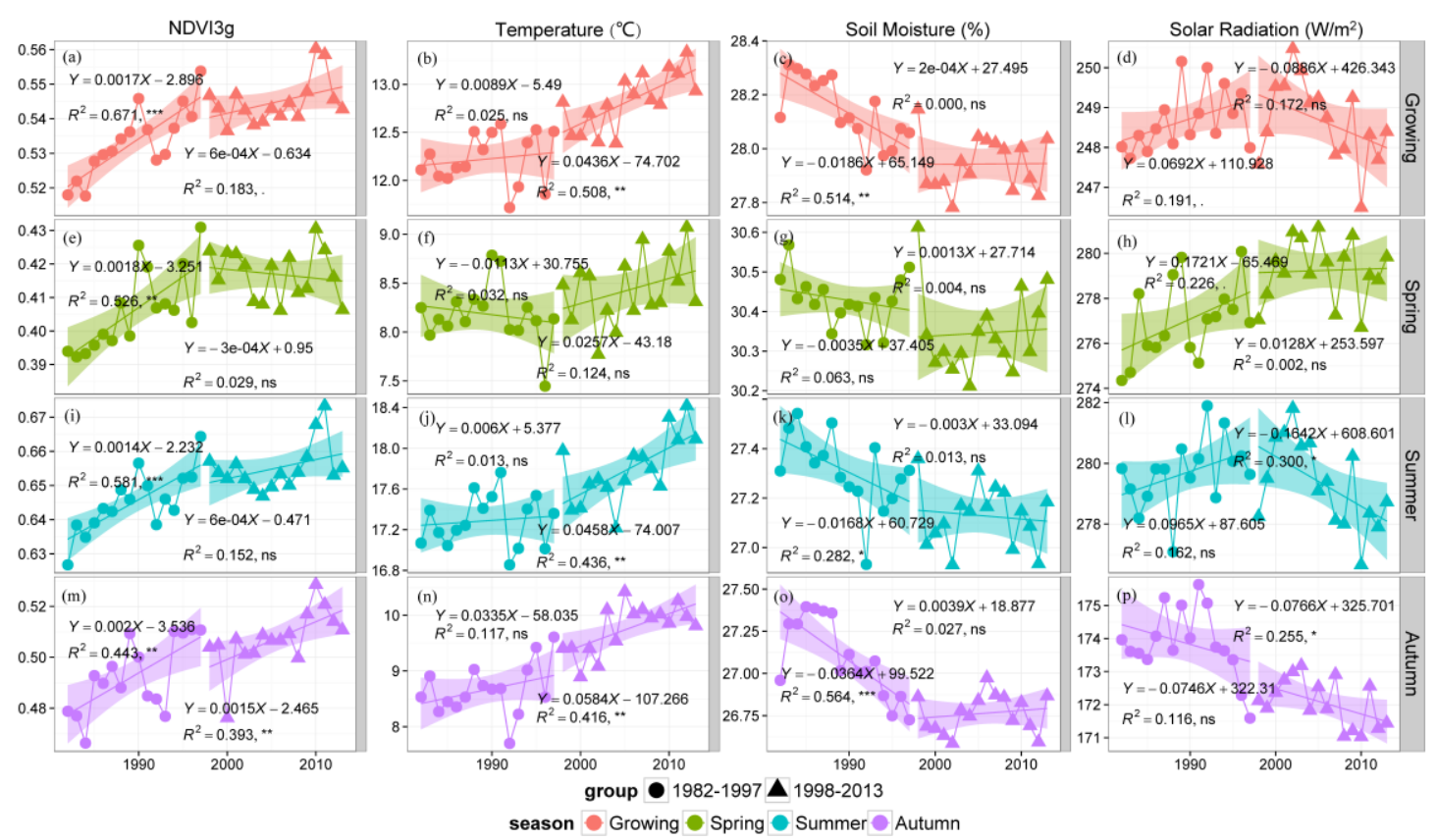

Fig. 1 Linear relations between NDVI3g and temperature, soil moisture, solar radiation during the growing season (April to October), spring (April to May), summer (June to August) and autumn (September to October), respectively. *** denotes significant at $99.9 \%$ confidence level; ** at $99 \%$ confidence level; * at $95 \%$ confidence level; at $90 \%$ confidence level; and ns denotes not significant. Shadings represent linear regression $95 \%$ confidence intervals. 


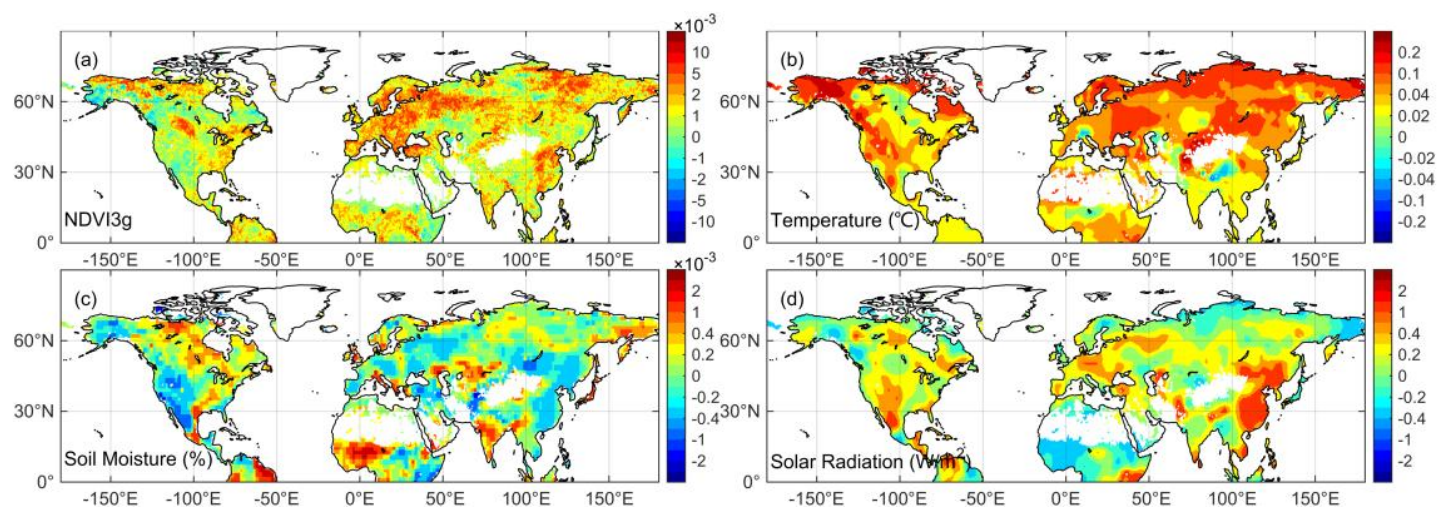

Fig. 2 Linear trends of NDVI3g during the growing season (April to October), temperature, soil moisture, and solar radiation during 1982-2013. 


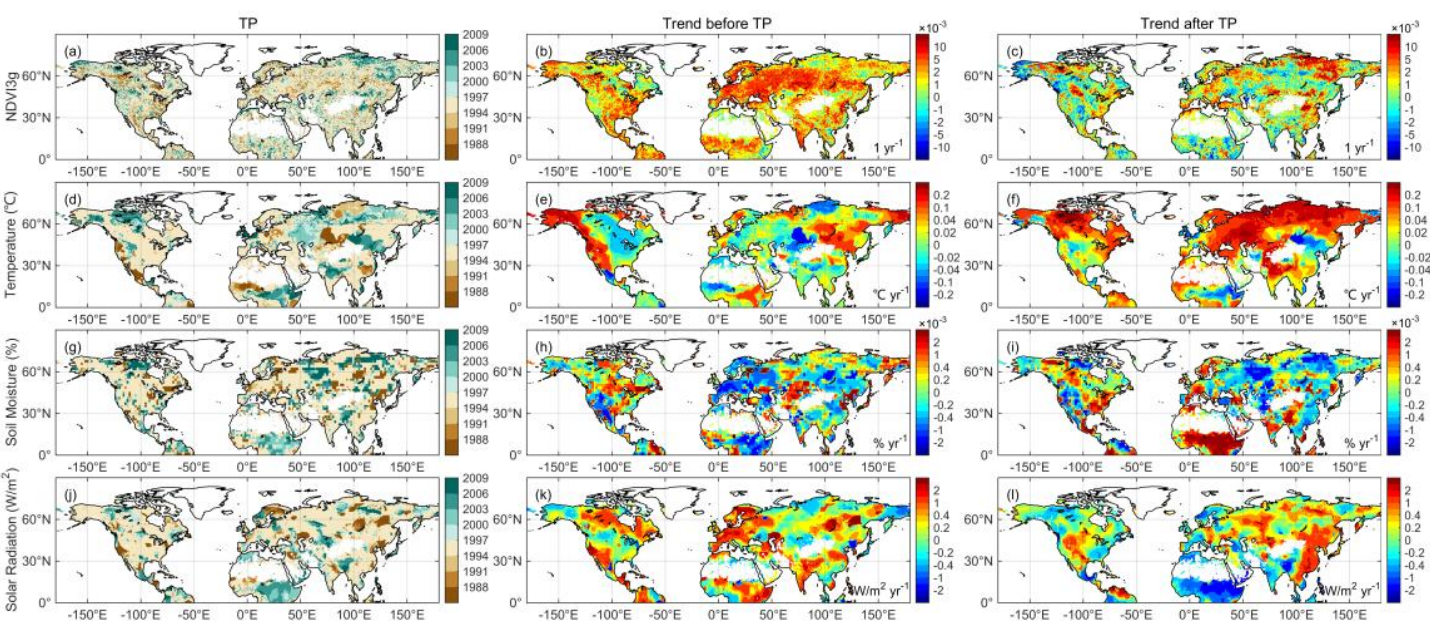

Fig. 3 Change points and trends prior and posterior to change points of NDVI3g during the growing season (April to October), temperature, soil moisture, and solar radiation. 


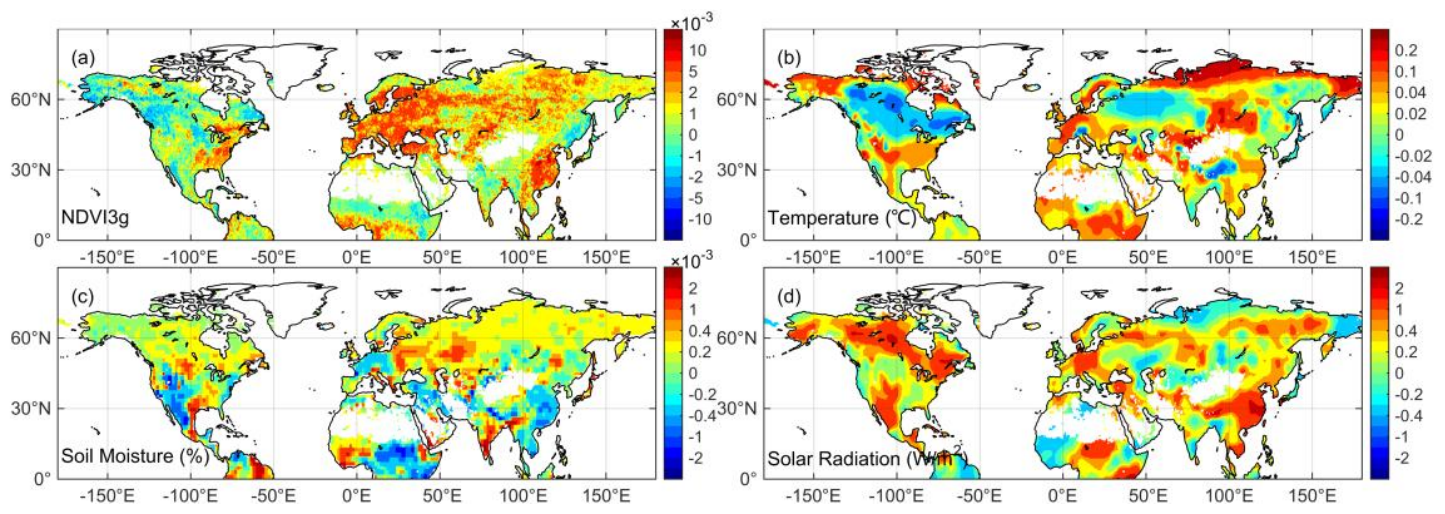

Fig. 4 Linear trends of NDVI3g, temperature, soil moisture, solar radiation covering a period of 1982-2013 during the spring season (April to May). 


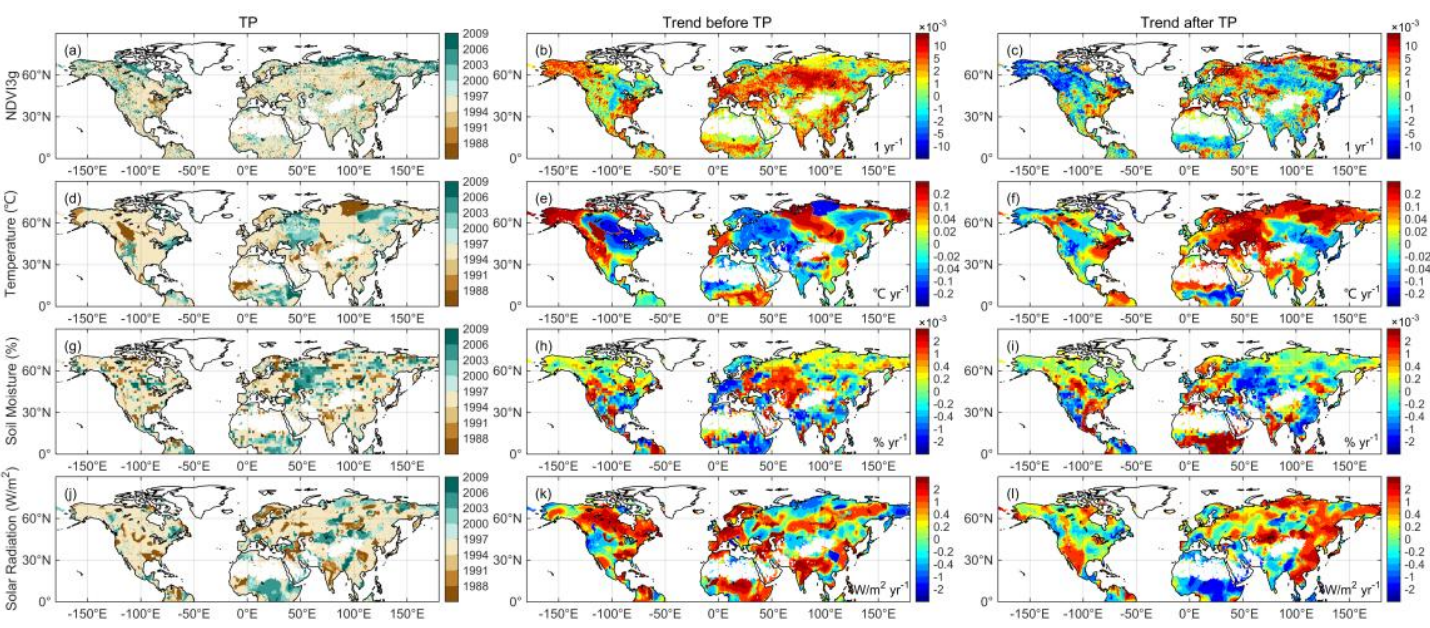

Fig. 5 Change points and trends prior and posterior to change points of NDVI3g, temperature, soil moisture and solar radiation during the spring season (April to May). 


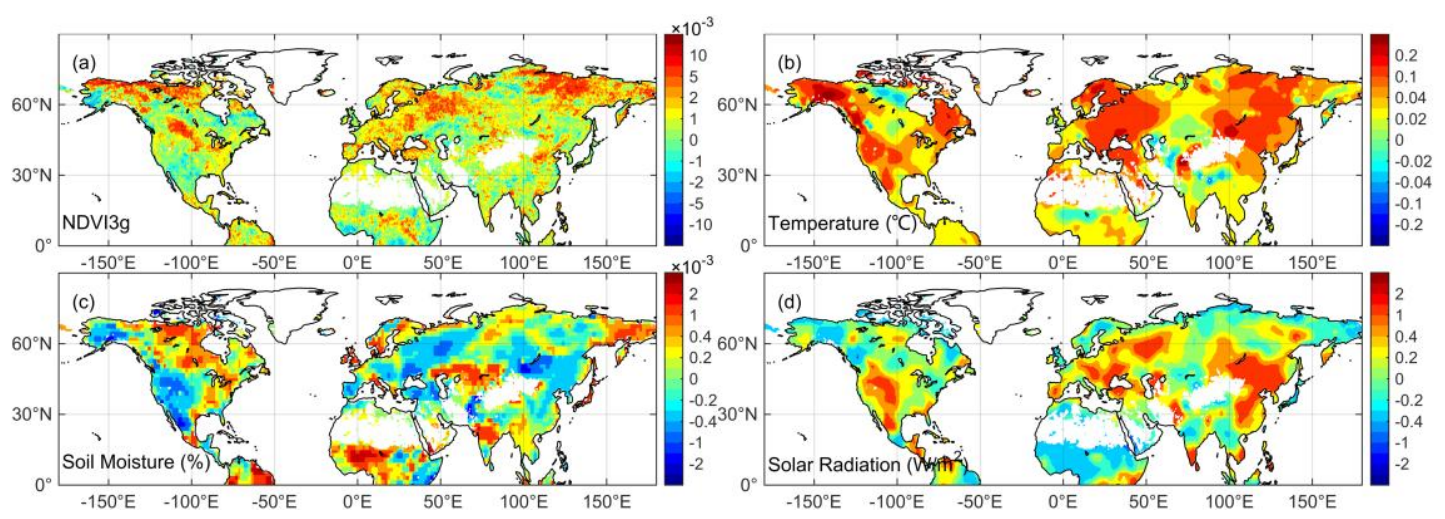

Fig. 6 Linear trends of NDVI3g, temperature, soil moisture, solar radiation covering a period of 1982-2013 during the summer season (June to August). 

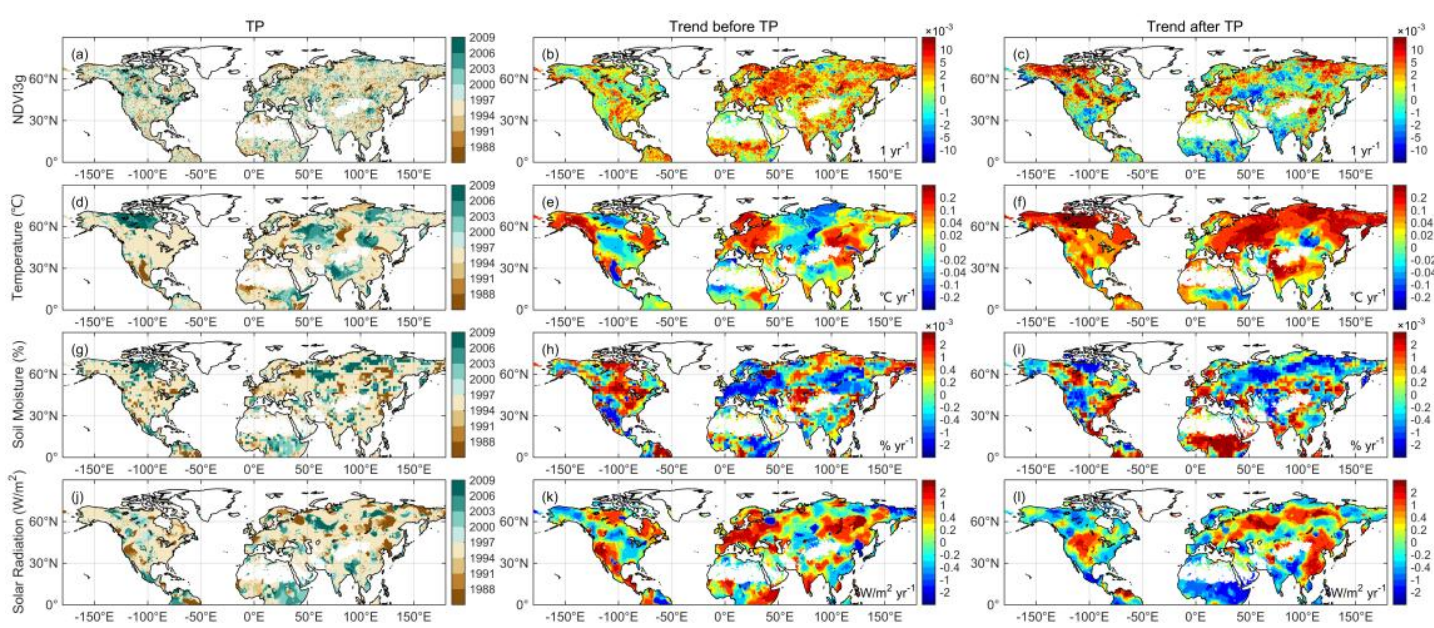

Fig. 7 Change points and trends prior and posterior to change points of NDVI3g, temperature, soil moisture and solar radiation during the summer season (June to August). 


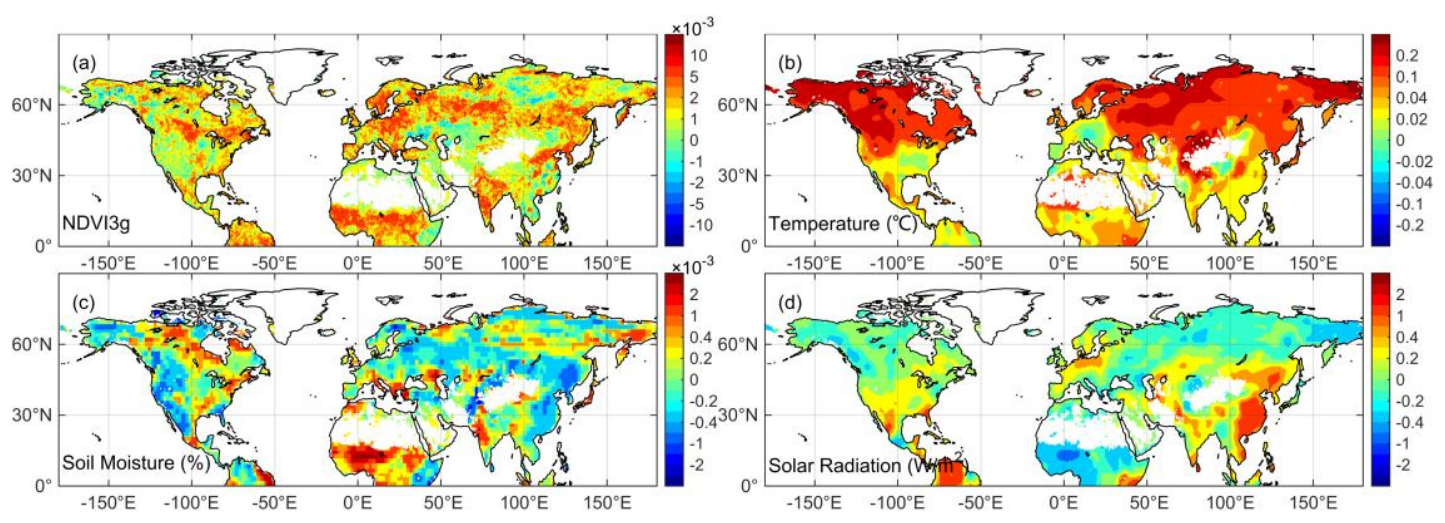

Fig. 8 Linear trends of NDVI3g, temperature, soil moisture, and solar radiation covering a period of 1982-2013 during the autumn season (September to October). 

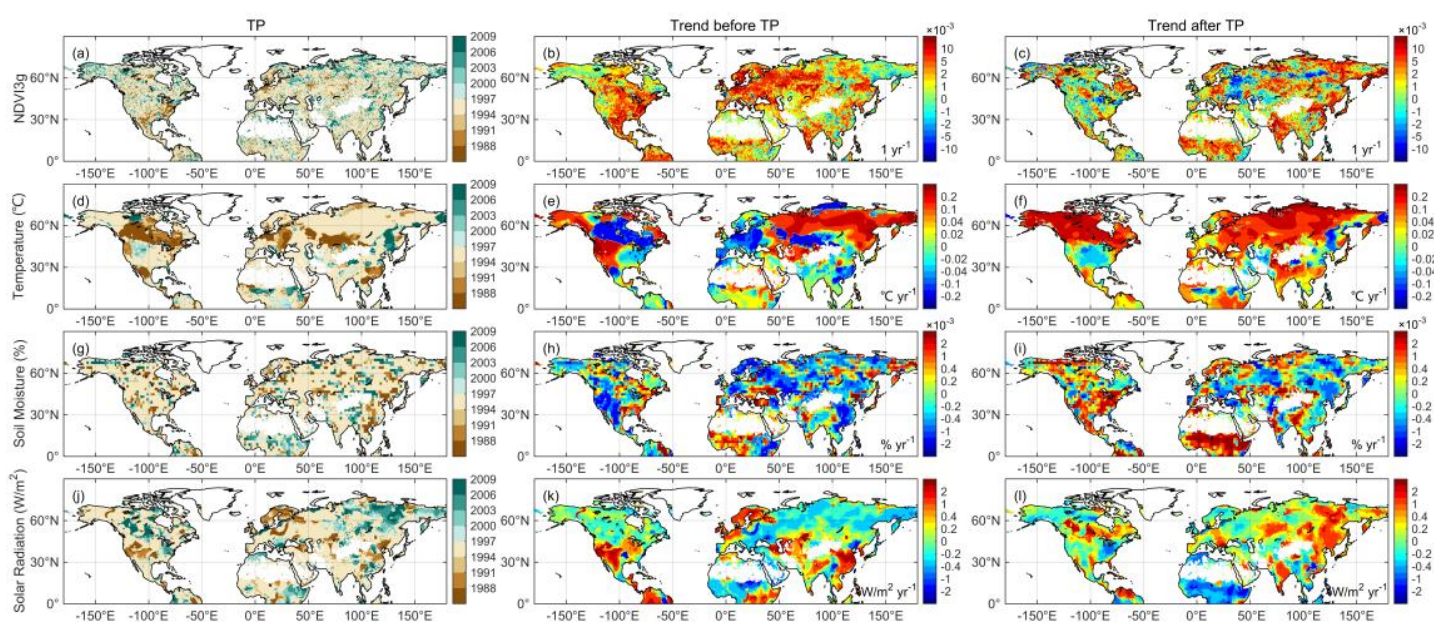

Fig. 9 Change points and trends prior and posterior to change points of NDVI3g, temperature, soil moisture and solar radiation during the autumn season (September to October). 